\title{
Preface to the Special Issue on short pulse fiber lasers
}

In the last two decades the fiber laser has evolved from a laboratory curiosity to a viable tool in an increasing number of applications in such diverse areas as material processing, atmospheric monitoring, high energy physics, medicine, telecommunications, and defense. The reasons for the growing acceptance of fiber lasers lie in the combination of their many attractive features. Indeed, fiber lasers are together power efficient, compact, light weight, versatile and reliable. Initially, the development of fiber laser technology was led to challenge the dominance of well entrenched solid state lasers used in the lucrative manufacturing industry. Traditionally, the emission wavelength band of interest was mostly limited to the near infrared (NIR) region (i.e. from 1 to $1.6 \mu \mathrm{m}$ ). More recently, extensive fiber laser R\&D advances have extended the laser applications to a broader spectrum, from the ultra violet (UV) to the mid-infrared (Mid-IR) wavelength region, and investigated the specific advantages associated with different pulse widths, from ns to fs, and different operating regimes.

Today, R\&D on short pulse fiber lasers is moving so quickly across so many diverse scientific and industrial fields, that it is clearly difficult for the researchers to cover all the breakthroughs and advances. Therefore, our initial purpose in proposing this special issue of the Optical Fiber Technology Journal was to provide an overview on some of the trends and advances on the topics of short pulse fiber lasers.

Our special edition includes sixteen (16) invited papers from distinguished researchers from both industry and academia from different parts of the world. In each contribution the authors present an overview of the latest advances in their specific research area. The topics covered can be grouped under four major topics:

- Non-conventional pulse dynamics and soliton source optimization

- $2 \mu \mathrm{m}$ mode-locked and Mid-IR novel fiber laser designs

- High power fiber laser designs for sensor applications

- Enabling fiber laser components and technologies
We hope that the contents of this special edition will provide OFT readers insightful overviews on the state of the art in short pulse fiber lasers and will inspire new studies and applications in this exciting field.

I would like to acknowledge my co-editors for their continuous support and contribution in the process of bringing the special edition to a successful outcome.

The whole Editing Team would like to express their thanks to all the authors for their unique contributions and to the many reviewers for their careful and timely evaluation of the sixteen invited manuscripts.

Finally, we are grateful to Bertrand Desthieux, the Editor in Chief, for his patience and guidance: We are well aware that we would not have made it without Bertrand's support, who, not only promoted the topics on the short pulsed fiber lasers, but fueled our determination in completing the process and made sure to minimize any red tape along the way.

Managing Guest Editor Jean-Marc P. Delavaux Cybel, LLC., USA E-mail address: jm@cybel-llc.com

Guest Editors Philippe Grelu Université de Bourgogne, France E-mail addresses: philippe.grelu@u-bourgogne.fr

Wang Pu

Beijing University, China E-mail addresses: wangpuemail@bjut.edu.cn

Fatih Ömer Ilday Bilkent University, Turkey E-mail addresses: ilday@bilkent.edu.tr

Available online 3 October 2014 